Haunted Psychologies: The Specter of Postmodern Trauma in

\title{
Bakemonogatari
}

\section{Barbara Greene}

Volume 2, Pages 243-281

\begin{abstract}
The anime adaptation of the light novel franchise Bakemonogatari was released in 2009. The story revolves around the character Araragi Koyomi, a high school student in his senior year who encounters a powerful vampire during a school break and is transformed into a semi-supernatural being himself. However, this is not merely an example of a supernaturally-focused anime, but rather is a discussion on the impact of capitalism on the subjectivity of the individual. The narrative and experience of viewing Bakemonogatari is a commentary on the trauma of postmodernity and otaku consumption's failure to remediate the objectification of consumer-capitalism. The series' design and narrative choices is designed to attract otaku, to whose consumption these patterns are designed to appeal, and thereby give warning to otaku concerning the potential dangers posed by their approach towards media. The characters in this series are possessed by Specters who dredge up and yet simultaneously suppress this traumatic state of existence in a world without catharsis and without justice. Otaku, attracted to moe-kyara to escape the drudgery and misery of the three-dimensional world, are shown that this escape itself is a form of harm-like Araragi, they turn meaning into a form of self-flagellation and heap untold suffering on the moe-kyara towards which they are inextricably drawn.
\end{abstract}

Keywords: Bakemonogatari, Postmodernity, Otaku, Moe-Kyara, ConsumerCapitalism, Identity

Author Bio: Barbara Greene received her Ph. D from the University of Arizona in 2017. She is currently an Associate Professor at Tokyo International University where she teaches courses on Japanese literature and popular culture. Her research interests include the influence of popular culture on collective memory and postmodern identities in fiction. She has been previously published in Critique: Studies in Contemporary Fiction and the Japanese Journal of Religious Studies.

This work is licensed under a Creative Commons Attribution-NonCommercial 2.0 


\section{Introduction}

The anime adaptation of the light novel franchise Bakemonogatari was released in 2009. In the following twelve years, twenty-two more series of various lengths subdivided thus far into three seasons were produced with more scheduled for future release. ${ }^{1}$ The story revolves around the character Araragi Koyomi, a high school student in his senior year who encounters a powerful vampire during a school break and is transformed into a semi-supernatural being himself. As a result, he and a harem of young women who are also tied to the supernatural engage in exorcisms and interpersonal struggles. However, the series itself is not told in chronological orderAraragi's battle with the vampire, entitled Kizumonogatari, was not released as an anime adaptation until 2016, nearly seven years after the release of the franchise's first season of Bakemonogatari. ${ }^{2}$ Furthermore, events occur out of chronological order within the episodes; cut-scenes and text flash across the screen, photography of realworld locations and people are incorporated into the animation, objects are endlessly copy-pasted to create the background, art styles dramatically and jarringly transform and then revert to the original. The series' imagery constantly accosts the viewer, bombarding them with visuals and splashes of primary colors. But to what purpose? The narrative and experience of viewing Bakemonogatari is a commentary on the trauma of postmodernity and otaku consumption's failure to remediate the objectification of consumer capitalism. The series' design and narrative choices are designed to attract otaku, to whose consumption these patterns are designed to appeal, and thereby give warning to otaku concerning the potential dangers posed by their approach towards media. 


\section{Otaku as a Symptom}

To fully understand Bakemonogatari as a reflection of the postmodern, one must understand its position as part of the larger, otaku-orientated media culture to which it belongs. Otaku, a notoriously tricky term to define, is best understood as a way of being in which an individual is drawn to the mass-produced fictional worlds generated by the Japanese media industry. 3 Otaku are different from collectors or hobbyists-as they prefer fictional worlds and elements that can never be tangibly possessed, unlike their collector and hobbyist counterparts. 4 This sub culture now interacts with media, not as a series of original and unique texts, but rather what Azuma describes as a large-scale database structure constructed around a myriad of mass-produced and hardly differentiated pop cultural products that can be broken into component parts and then reassembled according to need and desire. Even the existence of an original work has ceased to exist as contemporary anime productions and related goods are pure simulacra created by an industry focused on generating an infinite multitude of profitable copies, a fact of which otaku are fully aware. 5 However, for otaku, the artificiality of this aesthetic endeavor is unimportant, as it is the database nature of this medium that is the draw. ${ }^{6}$ While this acceptance of the artificial is partially grounded in a type of sexuality in which the appeal of flat images becomes a locus of self-exploration, according to Saito, it is also due to the fact that these fictional worlds evoke an emotional resonance that is not found as expediently within reality. ${ }^{7}$

A key part of this appeal is that of the moe-kyara, a highly stylized yet uniform character design that has been particularly profitable for manga and anime producers. These flat images, readily if not automatically divorced from narrative and context, create allusions and linkages between unrelated series that allow for the arbitrary 
creation of a chain of signification that only possesses meaning according to individual interpretation. ${ }^{8}$ Moe-kyara have become prevalent in anime and manga over the last twenty years as they, by their flat nature, allow for a dissection of society and a questioning of hegemonic social values that otaku often find stifling. ${ }^{9}$ Many of the character designs of Bakemonogatari, from Araragi's antenna hair to Hanekawa's appearing and disappearing cat ears, are common moe-kyara motifs. ${ }^{10}$ These design choices allow for easy access to the database, as with standard character designs, it becomes easy for otaku to dissect the moe-kyara into their component pieces and to thereby create and project meaning. ${ }^{11}$ This individualized creative act, drawn counterintuitively from simulacra, allows otaku to possess their own iteration of the fictional worlds that draw them in and creates a new way of being that provides them with meaning. ${ }^{12}$

Moe-kyara thereby create entry-points into the fictional, allowing otaku to freely explore worlds that are otherwise blocked to them (either due to their unreality or present impossibility).13 Moe-kyara have even become a type of social strategy, with youth creating their own kyara personas that allow them to create relationships with others in reality. Through the mediation of kyara, these relationships become smoother. ${ }^{14}$ Notably, this is not due to social anxiety, but rather is a means of better tailoring individual responses to the perceived need of others. ${ }^{15}$ Otaku consumption of a fictional world that is overlaid onto reality via a close affiliation with the fictional and the consumption of goods tied to the media industry has thereby become extended into interpersonal relations outside of the media itself. The fictional has now become a tool for survival in a changing world. This is a symptom of the interpersonal dysfunction created by consumer-capitalist societies; personal satisfaction is the primary driver for 
individuals within this system, and yet this creates a form of inescapable anomie. ${ }^{16} \mathrm{Moe}$ kyara thereby becomes a means of attempting to reconnect-being semi-virtual, moekyara promise a form of interpersonal relationship between itself and the otaku that could never falter as it is ultimately entirely under the control of the otaku instead of being negotiated between two independent entities. ${ }^{17}$

The necessity of this level of mediation is an outgrowth of contemporary Japanese society. Commentators have noted that by traditional standards, youth often seem to be asocial. However, youth are quite social through the mediation of the internet or through media in general. ${ }^{18}$ This, too, is a symptom of consumer-capitalist societies, where escape into virtual or parasocial relationships offers a sense of connection without the potential hardship of interacting with other subjects. ${ }^{19}$ This can even be seen with the types of moe-kyara who appear in media-self-insert moe-kyara who replicate otaku behavior have become increasingly common, as is the case with the character Araragi in this series and Homura in the franchise Madoka Magica. ${ }^{20}$ However, the exploitation of moe-kyara is also a source of guilt as, by projecting their own personal needs and individual traumas onto the fictional characters with whom otaku experience close emotional relationships, the otaku become complicit in the propagation of misery. ${ }^{21}$ Otaku are tied inextricably to the desiring-machine ${ }^{22}-$ the mode of consumption and identity derived from contemporary Japanese popular media-and yet seek to become one with the body-without-organs, the moe-kyara that serve as a locus of meaning, the production system itself as represented as its major anthropomorphized product. ${ }^{23}$ However, joining the desiring-machine with the bodywithout-organs is an impossibility, a trauma of failing interpersonal relationships in 
consumer capitalism built upon another trauma-that of the postmodern conditionwhich leads otaku to the use of media as a tonic for a condition exacerbated by media. Interestingly, the otaku insert moe-kyara is the only liminal character within the Bakemonogatari narrative: he is neither fully human nor fully monster. Attacked by a vampire during his Golden Week holiday break, Araragi is able to retain elements of the supernatural voluntarily by retaining a connection to the now substantially weakened Shinobu-a once powerful vampire who existed in the guise of a beautiful, adult woman, but who is now trapped in the body of a small child. In her original form, Shinobu possessed none of the characteristics common among moe-kyara-she was adult rather than childlike, and sexy rather than cute. She represented in her original form the vampiric nature of the Adorno and Horkheimer's Culture Industry, rendering her victims powerless under her thrall. ${ }^{24}$ But now she is reduced to existence as a mopey moe-kyara who sulks in a corner like a scolded child, serving Araragi's needs. As an otaku, he is comfortable with his bifurcated existence between the two-dimensional world of the supernatural and his three-dimensional hyperreal reality. ${ }^{25}$ It is the otaku, with their database approach to popular culture, who are able to render the Culture Industry into an entity over which they hold power - transforming the vampire into a moe-kyara. ${ }^{26}$ Notably, after the attack, Araragi is surrounded by a harem of other moekyara, a revolving door of young women in desperate need of his help to exorcize them from the grasp of a variety of spiritual possessions. Hanekawa, one of the myriad of possessed girls, explicitly states that Araragi likely has some form of glamour due to his connection with the vampiric that attracts these young women. Like otaku, Araraki surrounds himself with moe-kyara. 
Within Bakemonogatari, Araragi is the moe-kyara stand-in for otaku, his liminal nature is likely a statement of otaku. Not fully a member of the vapid real world in which he lives, Araragi is able to tap into a more exciting and fulfilling realm that is visible to those willing to perceive it (as long as they can shift their perspective). Like otaku who find a multi-layered combination of the narrative of the real to be fulfilling, Araragi elects to retain this connection to the supernatural despite the hardships it can cause. This decision draws him towards an array of moe-kyara who give him greater access to the database world that is the supernatural in the universe of Bakemonogatari. Like the culture industry that spawned anime, Oshino, the slippery exorcist who saves Araraki from his vampiric transformation, is transformed into a moekyara servant by Araragi in the same way that otaku consumption radically altered the media landscape.

Even among Araragi's harem of possessed moe-kyara schoolgirls, there are only two who possess "real world" counterparts-Senjougahara and Hanekawa. In the opening credits and music for Bakemonogatari, the character of the possessed female moe-kyara is the focus-never Araragi. As an otaku insert, his internal life is left comparatively blank in order to allow the viewer to better project themselves onto him. However, his two key relationships take place with these two schoolgirls, and so they are the moe-kyara who exist most closely in line with reality. These two moe-kyara are the ones who will reside, via their connection with the otaku self-insert character, the closest to reality itself, and so their opening credit scenes use real-world photography as part of the bricolage: Senjougahara's curse is weightlessness, and yet she stomps throughout photographs of real-world locations as a giant, and Hanekawa is a faceless human model haunted by the cartoon of a cat. 
As otaku possess a dual- layered approach, forever looking in the breaks in aesthetic choices and design in order to grasp hidden meaning within an anime, the decision to incorporate photography indicates to the database-minded otaku that there is a larger commentary within this narrative that they must seek out. ${ }^{27}$ However, this commentary contains within itself a warning to the otaku-one that is similar to that of Madoka Magica, as Hanekawa's demonic cat, the only truly malicious supernatural entity within Bakemonogatari, states that humans and the supernatural can never mix. Araragi, by remaining in his liminal state, selfishly upsets the delicate equilibrium between the two worlds and threatens the world order. Yet, he cannot help but do so as the world itself is already unbalanced.

\section{The Collapse of Knowledge into Otaku Irony}

Within the series, the characters' conversations, while cogent, come across as a form of collage. Dialogue is spliced with cut scenes where text expositing the thoughts or emotions of the characters splash across blank screens, body parts, or still images of objects or landscapes. Rarely is a character shown actually uttering something of importance; rather, vital speech is disconnected from the speaker, existing as a voiceover over these randomly selected images. In contrast, inane word-play and superfluous conversations are shown in the intense shot-reverse shot one would expect for deep character conversations. Nor is the dialogue realistic; rather, it comes across to the viewer as a high-speed word game in which each character attempts to outwit or outmaneuver their interlocutor. The dialogue itself gives an impression that it somehow stills propels forward the narrative and deepens the characters involved, yet even this is simulacra and merely another level of language games. 
This is part of the larger fragmentation of meaning and context within the series. Just as the dialogue exists in a form divorced from its context, the landscape consists of wide blank spaces punctuated by copy-pasted objects in bold, solid colors. The series assaults the viewers' senses and gives a sense that of fragmentation despite the narrative's eventual flow into a cogent story. This is unsurprising as not only has anime has become well known for its use of montage and collage, but also because the series is yet another anime adaptation of a light novel ${ }^{28}$ and retains elements of the narrative form common in this genre. Yamada notes that while disjointed narration has become a common motif in contemporary anime, this trend began in the 1980 s with genbunichi ${ }^{29}$ literature $3^{30}$ Bakemonogatari is merely taking this aspect of contemporary fiction to its most extreme logical end that still retains a narrative function.

This new narrative form is a natural outgrowth of the postmodern as, despite the collapse of the Grand Narrative, storytelling retains its value as a means of transmitting understanding and creating connection. Narrative serves to exchange information and attempts to garner understanding according to a series of rules, formulas, and rhythms that in turn expand outward to create social bonds and connections. ${ }^{31}$ However, the evaluation of narrative has shifted as contemporary narratives are judged according to their usefulness, whereas before, a particular argument was judged according to its adherence to the Grand Narrative. $3^{2}$ Within Bakemonogatari, there exists no transcendental truth behind the supernatural-merely a series of weird objects whose power depends solely on context. The supernatural is thereby akin to narrative in postmodernity-useful when needed and to be exorcised from perception when unwanted. 
With the decline of the Grand Narrative and the injunction to judge narrative according to its immediate utility, social bonds have also begun to dissolve. Relationships become contextual and maintained according to their need, with discourse transitioning into a form of a game in which members are not attempting to garner understanding but rather compete via a set of rules that may not be entirely shared. 33 This is demonstrated not only through the dialogue of the characters in Bakemonogatari, who engage in an endless series of word-games that the protagonist consistently fails to win, but in their relationships as well. Characters are constantly jockeying for social position and trying to establish their identity through the manipulated perceptions of others, wishing forever for signs of acclaim and yet constantly on guard for signs of disapproval. 34 Interpersonal relations are categorized according to need and desire. Even seemingly close relations such as boyfriendgirlfriend or brother-sister are merely signals to shift the type of rules to which the word play adheres.

This flattening of discourse into a game is not limited to the interpersonal realm. In postmodernity, knowledge itself has been delegitimized and requires constant verification, the requirements of which shift according to context. 35 Truth has ceased to exist as its own entity, but now is merely an aspect of a useful narrative. ${ }^{6}$ Within Bakemonogatari, this antagonism between truth as an objective entity and truth as something that varies according to context is a constant source of tension. Midway through the second series, Nisemonogatari, the lead character's younger sister, is revealed to be a form of a changeling-a type of supernatural creature that inserts itself within families as their "child," only to transform into a potential threat as it grows. Yet, when exorcists arrive to remove the false sister from his household, Araragi, claiming 
that his sister's authenticity is irrelevant to him, fights them at great personal cost, stating that she is real to him. Objective truth, even when it is in regards to a danger to the collective, is irrelevant when it comes to personal desires.

Narrative within contemporary Japanese fiction has even become detached from the "truth" as defined as the meaning of authoritarian intent, and instead focuses on relative "truth" determined by the meaning as interpreted by the individual viewer. 37 This transition is part of the larger movement away from the Grand Narrative and the rise of postmodernity, as well as the fragmentation of society and a sense of shared purpose. Even individual actions that are intended to give meaning to personal existence become merely a source of frustration and fatigue. ${ }^{38}$ This cynicism concerning personal development and the merit of one's sacrifices is repeatedly highlighted. Araragi continuously allows his body to act as a shield and a scapegoat for the ire of the supernatural, even to the point of being torn asunder and disemboweled. He is never truly in danger, though; as a semi-supernatural creature himself, Araragi can take any punishment thrown at him without receiving any permanent damage.

Furthermore, this liminal state is something that Araragi elects to maintain as, at any time, he could elect to become fully human once more. Additionally, it is noted by multiple characters that these performative self-sacrificial acts are ultimately pointlessmore possessions will inevitably occur and even the apparently exorcised are never returned to their previous state. Araragi himself acknowledges that he is doing this for his personal satisfaction; he currently derives pleasure and meaning from these actions, and one day, may simply decide to stop. Like otaku, who, according to Azuma, have lost the sense of a transcendental other, such as "truth" or other similar concepts derived 
from Grand Narratives, the lead is merely engaging in a form of play that he can quit whenever it becomes tedious. 39

Otaku themselves are an outgrowth of the postmodern. Their identity is one that elects to affiliate itself with a form of hyperreality derived from the consumption of mass culture-a uni-directional form of socialization that avoids engagement with other individuals and further exacerbates the collapse of meaning. $4^{\circ}$ Like Araragi, who surrounds himself with a harem of different type of moe-kyara, otaku have given themselves the ability to tightly mediate their relationships with others and have created their own idiosyncratic Symbolic Order-a series of motifs and tropes that allow them to decipher texts according to a series of shared rules. ${ }^{41}$ This consumption pattern is merely an expansion of Lyotard's word-games writ large upon an entire mode of media consumption. That Araragi and those around him approach the world with cynicism is also an outgrowth of the otaku mentality-passion must be viewed through a lens of ironic detachment and zealotry is a source of derision and mistrust. $4^{2}$ This is why Araragi is drawn to Oshino, a disillusioned and lazy cynic whose clear manipulation of information and economic self-interest is worn on his sleeve, and who is rejected by the other exorcists. Oshino can be trusted to be untrustworthy while the other exorcists pretend to act for the benefit of others while secretly conniving, as they believe in some larger truth that they must manipulate others into accepting.

Economic precarity is a constant source of anxiety in the text. Senjougahara's family sunk into poverty due to her mother's connection to an exploitative religious cult. To obtain help from Oshino, the only capable exorcist in the series, the characters have to pay between $¥ 100,000-1,000,000-$ steep prices for high school students at an elite high school where part-time jobs are frowned upon. After the Lost Decade, 43 a youth 
underclass that lives in a state of precarity began to form in Japan. This has increased focus on the concept of a kakusa shakai-an unequal society that replaced the notion of Japan as a solidly middle-class society-and kakusa ishiki-the mentality of one who is constantly at risk of economic collapse and despair. ${ }^{44}$ Even the world of Bakemonogatari itself appears to be in a state of decay: construction projects dot the landscape, but all have been halted-perhaps stopped due to funding shortages. Even the seeming middle- class comfort of the moe-kyara is precarious, or even false. Araragi lives in a large home, but his parents are forever absent, working long hours. Senjougahara's family lives in a half remodeled home due to her parents' recent bankruptcy and divorce, and Hanekawa sleeps on the stairs of her family's home. Even the supernatural lacks a home-the shrines that once housed the monsters and spirits have fallen into disrepair. The consumer wealth that overshadows the characters is naught but a façade that hides a myriad of horrors both domestic and supernatural. Precarity underlines all modes of existence.

Out of this precarity within contemporary Japan has risen the Superflat Art Movement, a modern art style which takes the imagery of otaku media to lampoon consumer culture in a society riddled with insecurity. 45 This movement began with the artist Murakami Takeshi, who holds a Ph.D. in traditional Nihon-ga and has attempted to blur the lines between commercial and high art. $4^{6}$ Murakami's background in Edo-era art can been seen in the flatness of the movement's art style that mirrors the flatness of Edo-era aesthetics. Some critics have even noted that otaku culture appears to be reminiscent of Edo-era investments in pleasure and aesthetics, the tsujin. 47 Both contemporary otaku culture and that of the Edo-era tsujin were lifestyles predicated on consumption: one of media and the other of the pleasure quarters and theater district. 
These lifestyles both created a consumer culture that takes expression and flattens it into a superficial series of images without meaning. ${ }^{8}$ Unsurprisingly, the style of Bakemonogatari is heavily reliant on imagery taken from the Superflat Art Movementa doubled layer as an anime riffing off of an art movement that itself is riffing off of anime.

Notably, Superflat Art has also relied heavily on the lolicon, the sexualized imagery of prepubescent girls, due to its ubiquity in otaku-focused art. 49 Lolicon is commonly seen with moe-kyara, as sexualized moe-kyara are attractive to otaku and their form of sexuality. $5^{\circ}$ Araragi constantly worries that he will be accused of fetishizing the younger moe-kyara he encounters because as an otaku, will be accused of lolicon. Yet, he takes no precautions to prevent this perception; rather, he seeks out opportunities to engage in forms of semi-sexual play with these young characters. When exorcising one from a snake curse, Araragi and Suruga, a lesbian character has the possessed moe-kyara, strip her down to her underwear so that her body can be inspected. Araragi later publicly mishandles the underwear worn by this character. Araragi, after discovering that Hachikuji is a ghost and not truly a ten-year-old little girl any longer, sneaks up behind her to grope her chest. In the second series in the franchise, he also spends an extended period pinning his sister's body down to a bed to brush her teeth. Araragi, like otaku, is irrepressibly drawn to moe-kyara in a platonically sexual ${ }^{51}$ manner. ${ }^{52}$

This compulsive drive is a source of repeated embarrassment, adding another layer of commentary to otaku consumption; this form of consumption is an attraction and a repellant. With the decline of the Grand Narrative in the 1970s, there has been a transition into what Azuma has called the "Fictional Age" where the grand narratives of 
the past are recognized to be only that: stories that we tell ourselves and nothing more.53 Even the two main male characters, Oshino and Araragi, represent two separate generations of otaku. Oshino is drawn to and lives in narratives that exist outside of mundane reality and Araragi is drawn to moe-kyara and lolicon. ${ }^{54}$ For otaku, with their predilection for fiction as a means of socialization, the draw of well-constructed narratives that adhere to expectations has been increasingly strong. 55 This had led some scholars, such as Saito, to argue that otaku are not totally adapted to reality, but rather prefer a "multi-layered reality" that is partially mediated through texts and imagery. ${ }^{56}$ Within Bakemonogatari, this preference is built into the very world-building of the series. Characters' back-stories are fleshed out with multi-media montages that combine still imagery of real-world locations and human models, text splashed across the screen in bold lettering, digital graphics, and traditional animation in a variety of styles. Rather than explaining character history and motivation via dialogue or action, it is revealed to the viewer via monologue and montage. The viewer is also confronted by myriad signage hung almost weightlessly over frequently blank or impressionistic backgrounds that imply locations rather than traditional establishing shots.

\section{Postmodernity as a Source of Trauma}

Bakemonogatari's focus on endlessly recounting the past also highlights the very issue of attempting to narrativize, and thereby close, the past: attempting to create a linear and cogent story of past experiences simplifies them and destroys the many facets needed for critical reflection and understanding. New forms of approaching the past are needed in the postmodern age. 57 Bakemonogatari attempts to demonstrate new forms of addressing the past via the constant presence of a Specter-a being that stretches out from the past and into the present. Specters are a means of exploring traumas or 
anxieties too horrible to be approached head- on-oft-encountered in liminal spaces. ${ }^{8}$ The action of Bakemonogatari takes place primarily in these liminal spaces-roadways, derelict school buildings, shared public spaces, and entranceways are where its traumas reassert themselves.

However, the world of Bakemonogatari is also one forever trapped between the past of what was and the future of what may be as it is perpetually under construction. It is under constant, yet halted, construction-a world of stagnant consumption without identity. Characters meander through streets that are devoid of other persons. The only indications that the world may be otherwise inhabited are the infinitely replicated cars and trains that infrequently dot the background (but in which no passengers are ever visible). Araragi himself is aimless-a top student in junior high school, he has been unable to maintain his grades in high school and, despite being less than a year from graduation, has no clear plans for his future. A cold, alienated universe that crushes the spirit of once bright young men presages the mentality of the otaku and their shifting interests: where once this group was drawn to futuristic science fiction narratives of high adventure, they are now drawn to prurient titillation in order to mask, and simultaneously mirror, the grim reality in which they live. 59

The supernatural in Bakemonogatari reflects and embodies the trauma of desire. Suruga wishes to be more and possess more than others, and therefore, to her own horror, the supernatural creature that possesses her arm seeks to harm or kill those of whom she is jealous. In contrast, Hachikuji is harmless, and can be only seen by those who wish to be lost-pulled away from some personal trouble to spend the day fruitlessly aiding another and forgetting their own problems. The crab god who removes Senjougahara's mass believes this is helpful to her. ${ }^{60}$ Desire is required to experience the 
supernatural, yet desire itself is shown to be harmful as it offers no real solutions. Consumer capitalism and postmodernity promise solutions to unsolvable problems and create a false sense that the system is focused on you. ${ }^{61}$ There supernatural therefore is no longer a locus of the transcendent or great truths, but simply another hyperreality devoid of true satisfaction and meaning.

This is partially why otaku are drawn to narratives reliant on some form of magical realism, as it is a genre that can take the mundane world and its myriad flaws and elevate it to the sublime. ${ }^{62}$ Magical realism draws in readership from the margins of society as it serves to mitigate trauma and also allows for multiple points of interpretation. ${ }^{63}$ For otaku, drawn to narratives that can generate a multiplicity of meaning, magical realism is a perfect form of escape, offering endless new vantage points and interpretations with each new entry and re-watch. Bakemonogatari, with its media mix and atemporal nature, not only offers numerous adaptations and series from which a viewer can choose but also provides a form of slow revelation. As each new character is introduced, so too is their individual trauma slowly revealed. Moreover, this new trauma builds off of the trauma of previously established characters, intertwining in an increasingly elaborate realm of re-traumatization and temporary catharsis. These stories are told out of order in order to enhance their emotional impact, as seen with the introduction of the character Hachikuji Mayoi, a small child accidentally killed while attempting to locate her estranged mother on Mother's Day. Not only is her own particular trauma slowly and haltingly revealed, but so is that of the three characters that she encounters in the arc. Araragi, Senjougahara, and Hanekawa are also alone on that day and wander the streets as they have no mothers with whom they can celebrate this commercial holiday. 
This failed holiday highlights yet another node of trauma in postmodernity. Postmodern societies produce a network of consumer goods that are designed to target a specific demographic, which themselves are created by standardizing individuals into a specific typology. Baudrillard calls this phenomenon the conditioning of needs-an act that alters subjects to view their own identities through their patterns of consumption and the signification attached to these commodities. ${ }^{64}$ Mother's Day is one such conditioned need, and what are otaku, but an identity defined by the nature of their consumption of mass-produced media? Furthermore, while Bakemonogatari may be a world stripped of advertising, it remains one in which characters are endlessly bombarded by text. This constant stream of signification, tied to no signifiers, is necessary for the maintenance and existence of hyperreality. Hyperreal worlds manage to be overwhelming, yet simultaneously flattened and simplified, in order to create a sense of euphoria. ${ }^{65}$ Bakemonogatari is also a flat world that somehow manages to overwhelm the viewer, providing an escape from the hyperreality of postmodern life in a text that replicates and transforms the trauma of living within simulacra into something manageable and heroic.

Another aspect of Araragi that is noted by other characters is his seeming childishness. Despite nearing college age, he is frequently drawn to young girls in order to engage in rough-housing and appears to deny his own incipient adulthood. Furthermore, other than the exorcists and the supernatural, no adults save one grace the screen during the series. In postmodernity, where meaning and structure are simultaneously dissolved and re-ordered, there remain only two potential responses: childlike passivity and revolt. ${ }^{66} \mathrm{He}$ desires, which becomes a form of masochism in order to create a false sense of purpose and depth that gives the desire a meaning 
greater than itself. ${ }^{67}$ Araragi prevaricates continuously between these two nodes, acting as a self-sacrificing savio $r$ rebelling against injustice in one instance and playfully bullying children as if he were a naughty classmate in the next. However, this hyperreality creates another mode of existence that is barred to subjects such as Araragi-that of the Specter .

The Specter, whether originating out of fear or a desire for revolutionary change, coalesces out of anxiety and tension. It exists not of itself, but rather creates its existence out of the minds of others. ${ }^{68}$ The Specter is a form of repetition, constantly emergent and yet not fully formed. Like hyperreality, it has no substance besides that of a simulacra. 69 These are the creatures that stalk the world of Bakemonogatari, from the crab that allows Senjougahara to forget the hurt of her mother's betrayal without actually removing the memory of it, to the thwarted and unrequited love of Suruga that is turned toxic by her mother's destructive legacy-a demonic hand that grants twisted wishes, to the cold home of the unwanted orphan Hanekawa, the failures of familial love within a society in which such things cannot be commodified and are thereby viewed as worthless become in themselves ghostly.

Postmodern society is also imbued with a sense of malaise and economic decline in which individuals feel as if their existences as subjects rather than objects are precarious. This is particularly strong in Japan, where the Lost Decade stagnated wages for Japanese youth and ended the lifetime employment system that offered prosperity and comfort even into one's old age. ${ }^{70}$ And what are moe-kyara if not objects transformed in the minds of their consumers into the simulacra of a subject? Furthermore, society itself has become increasingly commodified; even socialization and relationships have become commodified as economic production becomes 
paramount. This transition has even sunk into the individual's very existence, as they, too, become a commodity that can become obsolete and disposable. ${ }^{71}$ Even the cityscape of Bakemonogatari dumbfounds its residents: its constantly shifting nature leaves the supernatural homeless, and even Senjougahara's home, which she left a mere three years before, has been razed to the ground. The only remnants of the past are the lines of roads that connect half-abandoned buildings and vacant lots with glossy storefrontsthe past can only be vaguely detected and yet is forever inaccessible.

Furthermore, otaku come into adulthood in a world in which the consumption of goods related to popular media, along with heavy consumption of the media itself, is a normalized practice. ${ }^{2}$ It is this backdrop that informs Bakemonogatari, where relationships and personalities appear to be based off archetypes rather than individuals. Senjougahara, Suruga, and Araragi both note at separate times that Oshino has a moe name, with Senjougahara claiming that he must have been so as a child. Senjougahara is described by herself and others as a tsundere ${ }^{73-}$ to the point where Araragi is given advice on how to treat her according to the tropes associated with this archetype rather than as an individual person. Later, there are extended conversations on how maido and anime characters work much harder than anyone realizes with no comment on the fact that only one is an actual position held by real people. It is no surprise that this fictional world is one haunted by Specters. Commodity fetishism goes hand in hand with the formation of Specters as commodities too begin to hold a value beyond their tangible use and cost. 74

The characters of Bakemonogatari exist in a world of identical copies - a world in which the objects that construct their environment are copy-pasted images replicated ad infinitum towards a hazy, yet somehow suffocatingly close, horizon. In 
postmodernity, society is constructed out of minute differentiations between standardized, mass-produced choices-whether one selects a particular color or feature is how one creates a self that is different, yet identical, to those around you. 75 Like the copy-pasted background and the collage that create the back-flashed montages, objects within postmodernity are constantly being updated and revamped. ${ }^{76}$ However, this constant access to identical objects that all promise fulfillment does not satisfy. Like the innumerable “danger” (危険) and “caution” (注意) signs that hang unendingly in the background of the series, postmodernity is a world of ignored hazards - the claxons rendered silent by the flood of empty signification. Despite each commodity signifying jouissance, none can actually provide it, and this creates a compulsion to not only constantly consume, but also to endlessly explore in the hopes of locating the object that will offer enjoyment. 77 The constant re hashing of trauma in the form of Specters always promises a solution that will bring joy and satisfaction, but, as seen with Hachikuji, this catharsis is fleeting. Just as she is not freed from her spectral existence, rather promoted to a higher, and equally meaningless rank, so too are those in postmodernity trapped in an endless, deathless cycle of exploration and consumption.

The mimetic function of desire is also heightened within the narrative. By forming a dyad, mimetic desire allows for the object of desire that is unattainable to be erased. $7^{8}$ This is embodied through Araragi and Suruga, as they both desire Senjougahara, although she is not something either can truly possess. Her dominant personality and Araragi's inclination towards passivity means that in their romantic relationship, it is she who is the possessor and active agent. Her lack of same-sex desire or interest in close female friendships prevents Suruga from possessing her as a friend or a lover. By creating a dyad, Araragi and Suruga are able to create a stasis in which 
neither are consumed by the Specter of thwarted desire. Yet even this is collapsed. Stasis is never truly achieved, and the object of desire is never safely resolved. This, too, signals another change of postmodernity-that of the failure of catharsis. Even the relationship between Suruga and Araragi remains only partially resolved insofar as Senjougahara reframes their competition by giving them both a new narrative through which they can define their relationship with her. All relationships are mimetic in form, which is why the Specters all resemble the character or trauma that they are attached to in either name or signification. Araragi and Suruga maintain their uneasy equilibrium by mirroring each other's behavior. However, to experience catharsis, a sacrifice must be made-an act that is increasingly blocked by the nature of postmodernity and its claims of perfection without sacrifice that can only cause dysfunction. ${ }^{79}$ Neither Araragi nor Suruga make this sacrifice, and therefore, both remain in a state of tension. Through this mimetic rivalry, a form of simulated satisfaction is found. ${ }^{80}$ Araragi's constant efforts to sacrifice his body are mimetic but lack the level of sacrifice necessary to create true catharsis. There is no sacrifice he can make that would provide denouement. This is why the characters are forever trapped in a cycle of possession and exorcism.

\section{A Postmodern Possession and Sacrificial Crisis}

Postmodern societies create a world populated not by people but by objectscommodities that can be consumed and that weave a web of signification to create an impressionistic sense of emotion without any true meaning. ${ }^{81}$ The world of Bakemonogatari is absent of people and full of relationships predicated upon obtaining something that one desires and maintaining an image rather than building a connection. It is a world mired in the ideology of consumption-a world where salvation is promised through objects and media. ${ }^{82}$ Individuals in postmodern societies attempt to construct 
meaning and satisfaction by gathering together the objects that are associated with the images that the individual believes will create identity and pleasure. However, this act drives away true signification and replaces it with simulacra that move beyond the individual and drive reality away from interpersonal interactions. ${ }^{83}$ Anime is now merely a mirror of the real-world as it relies on the erasure of the subjective gaze of traditional visual media, in which an individual is an external observer, but instead creates a world in which the viewer's gaze is part of the world itself - thereby creating a world without external others. ${ }^{84}$ This medium has co opted the gaze of the consumer and incorporates them directly into its fictional worldbuilding.

Bakemonogatari is a world of usurped gazes, where the viewer is turned into a voyeur who peers into the unreality of a world in which the internal minds of the characters and the external world around are unseparated by boundaries. This is a world in which possession without the supernatural is already the normal state of existence; all are consumed by the commodities and objects around them. Possession by something supernatural-something beyond the realm of consumer capitalism-is what allows for a shift in consciousness that facilitates a sense of differentiation and the ability to sacrifice, something that allows for true meaning to be constructed, even if only temporarily. ${ }^{85}$ This is also tied to the discomfort of consuming a form of emotional reality through the mediation of a screen that usurps the gaze of the individual and takes it as its own. ${ }^{86}$ Cinema initially attempted to recreate a form of reality, however, TV would combine a variety of imagery in layers that accepted the artificial as a type of pseudo-reality. 87 Otaku are imprisoned by their screens just as Araragi has been by the supernatural. He and the otaku have both become voyeurs, peering into the inner minds of moe-kyara, and themselves the victims of a gaze of the objects around them that 
permeates their very being and colonizes their imaginations via postmodern consumer capitalism. 88

The series is also a world in which time and space have ceased to have meaning. With the decline of the Grand Narrative, the perception of linear time and the distinction between the past, present, and future have become blurred. Cogent narratives of causality have lost their luster and have been replaced with simulacra that combine both the past and the present into a single image. ${ }^{89}$ Time is constantly manipulated in anime: the actions of characters or images are slowed in order to create an emotional resonance as a means of giving flat images an artificial sense of depth, resultantly creating a medium that is essentially atemporal. 90 By layering flat image over flat image, a false sense of depth and movement is constructed that, in turn, manipulates and alters the perception of time for the viewer. ${ }^{91}$ This also creates an illusion that the animated worlds have weight and dimensionality-a false sense that they are somehow tangible. ${ }^{2}$ This is even highlighted in Bakemonogatari's first opening credit sequence, Staple Staple, which is Senjougahara's theme, as the animated character's feet crush and shake the streets of real-world Japan.

This element of animation has even seeped into reality, as architects have attempted to recreate the flatness and immateriality of the Superflat Movement in their designs. 93 The use of flat images that exist without relation to time is a critical aspect of postmodern society as it twists culture and media into a single temporal point: that of an unending present. 94 This collapsing of time, in turn, disrupts the chain of signification that allows an individual to construct meaning, shifting the coherence of perception away from rational thought and towards pure experience and the resultant emotional 
reaction. 95 Animation, as a form of aesthetic production, has taken a position as part of the economic production of society. ${ }^{96}$

Animation allows a subject to approach the specter of violence and death without confronting the reality of either. 97 Furthermore, animation also allows for form and space to be warped, creating a form of dimensional excess that, in turn, questions the nature of violence and turns the viewer into a voyeur. 98 This dimensional excess in animation transforms the experience of watching from just a simulacra of reality to a commentary on it. 99 The excesses of bodily harm and the results of violence in animation allow for larger meaning to be projected onto it. ${ }^{100}$ This creation of commentary and the allowance for multifaceted meaning is what draws the otaku to anime; this dimensional excess allows for the easy construction of a database into which they can retreat. ${ }^{101}$ In Bakemonogatari, the bodies that exist are nothing but excessive and fluid, but characters warp into a particular shape, be it a crab or snake. Bodies are transformed or torn apart-dimensional excesses that create tears that allow otaku viewers a glimpse into the database that promises meaning and depth, only to reveal another flat layer.

Dimensional excess is also involved in the creation of the female characters who make up the majority of the cast. Each adheres to a specific typology that signals personality and behavior at first glance. Moe-kyara are one such type -archetypal and largely female figures whose essences are divorced from a particular text and which allow for ready projection of individual desire. ${ }^{102}$ In part, moe-kyara allow young male otaku who are not comfortable with the gender expectations foisted upon them to adopt, albeit temporarily, a more feminine personality, in addition to offering a form of mediated and controlled relationship with something that could seemingly never 
disappoint. ${ }^{103}$ Araragi is noted throughout the series as lacking in masculinity, to the point that in his engagement with younger girls, he feels as if his masculinity is suspended as they easily outwit and manipulate him. He also wishes to serve as a nurturing and supportive figure in the lives of those around him: he does not wish to dominate or command as hegemonic masculine ideals in Japan uphold as the pinnacle of manhood.

This form of escape from societal expectations via moe-kyara is also grounded in the need to subvert the discipline that the Symbolic Order inflicts on subjects. By engaging in a type of relationship with the moe-kyara, otaku can escape the social order and also construct a temporary new order. ${ }^{104}$ Some scholars have posited this behavior as a form of sexual attraction towards moe-kyara, although Lamarre describes this as a form of platonic sexuality. ${ }^{105}$ In Bakemonogatari, however, this is made to be platonic at a higher level. Although Araragi may grope and manhandle the lolicon moe-kyara around him, he is the only character who is ever penetrated. Even when drawing energy from the vampire Shinobu, Araragi is the one who removes his clothing and lets his body be pierced. The attraction of this form of sexuality is grounded in moe-kyara's existence as creatures of pure fantasy (junsui na fantajii). ${ }^{106}$ All of the characters, even the audience-insert character Araragi, engage in this form of platonic sexuality as a means of escape from the rigors of reality. Bakemonogatari is a two-dimensional world that holds the trauma of the three-dimensional world in a type of emotional reality that cannot be grasped in reality. ${ }^{107}$

However, even these flat beings are haunted-they are postmodern beings haunted by the conditions of postmodernity. The Specter is a being caught forever in the act of becoming, just as the moe-kyara of Bakemonogatari are forever moving towards 
independence and adulthood and yet remain mired perpetually in the past. ${ }^{108}$ It is something on the edges of perception that is projected from within us, just as the demons and gods of Bakemonogatari are drawn to the moe-Kiara's repressed trauma. ${ }^{109}$ Like Senjougahara's crab, it exists everywhere and nowhere at once; all it needed was a small shift in perspective to become visible.

Similar to the supernatural beings in Bakemonogatari, the Specter emerges in many forms. ${ }^{110}$ Like moe-kyara, the Specter possesses a prosthetic body-an avatar that is affiliated with, but not of, the Specter. ${ }^{111}$ Throughout the series, characters grapple with the tangible and invisible, and wrestle with spirits who can only be discerned as floating text. In postmodernity, where the past bleeds continuously into the present, the Specter 's lack of temporality serves as a means of understanding the present and conceiving of a future. ${ }^{112}$ This bleeds into another aspect of moe-kyara as non-human or supernatural moe-kyara have become increasingly common over the last two decades, particularly as neutral figures that could be good or harmful depending on circumstance. ${ }^{113}$ By using the database nature of moe-kyara, who already existed as beings without narrative context and thereby already narratively divorced from time, their flat images are merged with the prosthetic body of the Specter and become an avatar for the trauma that the Specter represents.

Moe-kyara and the Specter are incorporeal doubles, as moe-kyara and the Specter both exist as projections of internal desires and sublimated trauma. For the Specter, this means the exorcism is an impossibility-just as none of the moe-kyara are ever really freed from the supernatural. ${ }^{114}$ Just like the vampire Shinobu, who seeks to create more vampires like her, hyperreality constructs endless clones: parents become matrixes, subjects are vanished, and death itself dies as the body is reconstituted 
ceaselessly. ${ }^{115}$ This is part of the destruction of the body in postmodernism, where the boundaries between the external and technological become blurred with that of the physical body. ${ }^{116}$ The body becomes naught but projection. ${ }^{117}$ And what are moe-kyara if not clones constantly projected onto one's internal imagination? Yet, even the moekyara are haunted by Specters, as Baudrillard states: "Of all the prostheses that mark the history of the body, the double is doubtless the oldest... it is an imaginary figure, which, just like the soul... makes the subject simultaneously itself and never resemble itself again... like a subtle and always averted death" ${ }^{118}$

Death is the one element of the supernatural missing from the world of Bakemonogatari; no one ever really dies in the series. Even the one corpse is merely a demon in the guise of a dead cat-a simulacra of death that springs to life with menace. With their excessive and infinitely replicated bodies, the characters in Bakemonogatari are blocked from experiencing something as permanent and real as death. Postmodernity has removed from the characters even this - promising endless recursion and cloning, suffering and struggle, in a world where objects overwhelm and relationships and personhood are simulacra. This denial of the permanency of death ties into the overarching theme of Bakemonogatari - there can never really be justice. The Specter is also tied to the messianic promise of justice at some distant yet inaccessible point. ${ }^{119}$ Glazier argues that with the Specter, Derrida creates a being not tied to orders of power or justification. ${ }^{120}$ The Specter offers an opportunity via its immateriality to point the way towards the negation of time and an ephemeral utopia. ${ }^{121}$ Bakemonogatari uses its specters to point forever towards a future where justice exists, where the victimization of Senjougahara and Sengoku could not only be avenged, but 
also erased. However, this erasure and justice is always immanent-yet never arriving. Justice will not and cannot come to this postmodern world; the Law no longer exists. ${ }^{122}$

Justice and sacrifice are mimetic in drive, seeking to control violence through the mediation of some form of transcendental other. ${ }^{123}$ This can give violence a form of meaning, making such acts sacred responses to a social crisis. ${ }^{124}$ Furthermore, for the sacrificial victim of violence, the sacrifice must bear some resemblance to the aspects being avenged-the part of humanity that failed to live up to the social ideal, that is also somehow distant from the community. ${ }^{125}$ Where the female characters are often the victims of male violence in Bakemonogatari, it is Araragi who takes on this role. He absorbs the violence wrought by the myriad specters that haunt the moe-kyara around him, but he is the only young, male moe-kyara who graces the screen. He is the scapegoat that allows the otaku to mitigate their guilt about projecting their own traumas onto female moe-kyara. ${ }^{126}$ Bakemonogatari thereby encapsulates a postmodern version of the sacrificial crisis-the collapse of boundaries that is rectified only by sacrifice. ${ }^{127}$

\section{Conclusion}

Bakemonogatari is a narrative that contains and yet is also itself a Specter . The narrative and aesthetic choices, designed to draw in otaku viewers, provide a commentary on the trauma inherent to postmodernity and consumer-capitalism. The characters are possessed by Specters who dredge up and yet simultaneously suppress this traumatic state of existence in a world without catharsis and without justice. Otaku, attracted to moe-kyara to escape the drudgery and misery of the three-dimensional world, are shown that this escape itself is a form of harm-like Araragi, they turn meaning into a form of self-flagellation and heap untold suffering on the moe-kyara 
towards which they are inextricably drawn. But there is no solution, no escape from this existence. Just like the supernatural in Bakemonogatari, media in reality may offer small escapes but possesses no transcendent meaning. Via postmodernity, reality itself is transformed into a database-and this transformation is the destiny of those living within it. 


\section{Notes}

1 “Monogatari Series Timeline and Watch Guide." Bakemonogatari Wiki, Acessed July 22, 2021, bakemonogatari.fandom.com/wiki/Monogatari_Series_Timeline_and_Watch_Guide\#Anime_Release_.2F_SHAFT_ Order.

${ }^{2}$ Ibid.

${ }^{3}$ Saito, Tamaki, Beautiful Fighting Girl (Minneapolis: University of Wisconsin Press, 2011), 11-13.

${ }^{4}$ Ibid, 16-18

${ }^{5}$ Azuma, Hiroki. Otaku: Japan's Database Animals, (Minneapolis: University of Minnesota Press, 2009), 38. ${ }^{6}$ Ibid, 47-53.

${ }^{7}$ Saito, Tamaki, Beautiful Fighting Girl (Minneapolis: University of Wisconsin Press, 2011), 27-30; Galbraith, Patrick W. Otaku and the Struggle for Imagination in Japan, (Durham: Duke University Press, 2019), 7.

${ }^{8}$ Azuma, Hiroki. Otaku: Japan's Database Animals, (Minneapolis: University of Minnesota Press, 2009), 47-51 ${ }^{9}$ Ibid, 42.

${ }^{10}$ Akgun, Buket, "Mythology Moe-fied: Classical Witches, Warriors, and Monsters in Japanese Manga," Journal of Graphic Novels and Comics (2019): 1-4.

${ }^{11}$ Azuma, Hiroki. Otaku: Japan's Database Animals, (Minneapolis: University of Minnesota Press, 2009), 44. ${ }^{12}$ Ibid, 20

${ }^{13}$ Galbraith, Patrick W. Otaku and the Struggle for Imagination in Japan, (Durham: Duke University Press, 2019), 10-13;

${ }^{14}$ Murai, Fumika, Okamoto, Yuko, Ota, Masayoshi, and Kato Hiromichi, "Relationship between Friendship with Self-Acknowledged Kyara and Self-Monitoring in Junior High School and University Students," The Clinical Study of Childhood Development. 15 (2021): 31-32

${ }^{15}$ Ibid, 37.

${ }^{16}$ McGowan, Todd. The End of Dissatisfaction: Jacques Lacan and the Emerging Society of Enjoyment, (Albany: State University of New York Press, 2003), 11-12; 69-70.

${ }^{17}$ Ibid, 70-71.

18 Oyama, Makiko, "The Role of Character in Interpersonal Relationships in Modern Youth - Consideration from Relationships in Family, Close Friends, Friends, and Involvement with Club Activities" The Journal of Kansai University of Social Welfare, 24, (2021):41-43.

${ }^{19}$ Gowan, Todd. The End of Dissatisfaction: Jacques Lacan and the Emerging Society of Enjoyment, (Albany: State University of New York Press, 2003), 11-12;70-71

${ }^{20}$ Greene, Barbara, "Reconstructing the Grand Narrative- The Pure Land of Madoka Magica," The Japanese Journal of Religious Studies, TBA (2021).

${ }^{21}$ Ibid.

${ }^{22}$ Deleuze and Gauttari defined Capital as the Body without Organs for those within a capitalist society (Deleuze and Gauttari 1977, 10-11). Otaku, as beings defined by their consumption of mass-produced, intellectual property that is a key form of Capital, are inexplicably drawn to the personified outgrowth of this Body without Organs - the moe-kyara.

${ }^{23}$ Deleuze, Gilles and Felix Gauttari. Anti-Oedipus: Capitalism and Schizophrenia, (London: Penguin Books, 1977), 5-11

${ }^{24}$ Horkheimer, Max and Theodor W. Adorno. Dialectic of Enlightenment: Philosophical Fragments, (Stanford: Stanford University Press, 2002),44-46

${ }^{25}$ Galbraith, Patrick W. Otaku and the Struggle for Imagination in Japan, (Durham: Duke University Press, 2019), 7.

${ }^{26}$ Azuma, Hiroki. Otaku: Japan's Database Animals, (Minneapolis: University of Minnesota Press, 2009), 38.

${ }^{27}$ Bolton, Christopher. Interpreting Anime. Minneapolis, (University of Minnesota Press, 2018). 
${ }^{28}$ Light novels are a type of novel targeted at a young readership that combines traditional prose with heavy use of manga-inspired illustrations that inform the text.

29 This genre of contemporary Japanese literature relies on the heavy use of realistic language and youth vernacular.

30 Yamada, Marc. "The Database Imagination of Japanese Postmodern Culture," Japanese

Studies, 33,1 (2013), 19-22

${ }^{31}$ Lyotard, Jean-Francois. The Postmodern Condition: A Report on Knowledge, (Manchester: Manchester University Press, 1984), 18-22.

32 Ibid, 27-29.

33 Ibid, 15-17.

${ }^{34}$ Girard, Rene. Things Hidden Since the Foundation of the World, (London: Bloomsbury, 1987), $244-245$.

${ }^{35}$ Lyotard, Jean-Francois. The Postmodern Condition: A Report on Knowledge, (Manchester: Manchester University Press, 1984), 37-39.

36 Ibid, 36.

${ }^{37}$ Yamada, Marc. “The Database Imagination of Japanese Postmodern Culture,” Japanese Studies, 33,1 (2013), 2224.

${ }^{38}$ Lyotard, Jean-Francois. The Postmodern Condition: A Report on Knowledge, (Manchester: Manchester University Press, 1984),37-38

${ }^{39}$ Azuma, Hiroki. Otaku: Japan's Database Animals, (Minneapolis: University of Minnesota Press, 2009), 71-72.

40 Baudrillard, Jean. Simulacra and Simulation, (Ann Arbor: University of Michigan Press, 1994), 80-81.

${ }^{41}$ Hack, Brett. "Subculture as Social knowledge: A Hopeful Reading of Otaku Culture," Contemporary Japan, 28, 1 (2016); 45

42 Ibid, 48-49.

43 The decade of recession following the burst of Japan's bubble economy in the late 1980s.

44 Ibid, 37-38.

45 Darling, Michael. "Plumbing the Depths of Superflatness," Art Journal, 60, 3 (2001); 83.

46 Ibid, 77-78

${ }^{47}$ Steinberg, Marc. “Otaku Consumption, Superflat Art and the Return to Edo,” Japan Forum, 16, 3 (2004);450-453.

48 Jameson, Fredric. Postmodernism, or, The Cultural Logic of Late Capitalism, (Durham: Duke University Press, 2013), 9 .

49 Darling, Michael. "Plumbing the Depths of Superflatness," Art Journal, 60, 3 (2001); 81-83.

50 Saito, Tamaki, Beautiful Fighting Girl (Minneapolis: University of Wisconsin Press, 2011); Lamarre, Thomas. "Platonic Sex: Perversion and Shojo Anime (Part Two)," Animation: an interdisciplinary journal, 2:1 (2007); 9-25.

${ }^{51}$ Both Saito and Lamarre note that, while the attraction to these characters is erotic in nature, it does not imply desire to engage in sexual congress but rather a form of highly aestheticized desire.

52 Saito, Tamaki, Beautiful Fighting Girl (Minneapolis: University of Wisconsin Press, 2011); Lamarre, Thomas. "Platonic Sex: Perversion and Shojo Anime (Part Two)," Animation: an interdisciplinary journal, 2:1 (2007); 9-25; Galbraith, Patrick W. Otaku and the Struggle for Imagination in Japan, (Durham: Duke University Press, 2019)

53 Azuma, Hiroki. Otaku: Japan's Database Animals, (Minneapolis: University of Minnesota Press, 2009 ), 73.

54 Ibid, 33-35.

55 Ibid, 74; 90-92

56 Saito, Tamaki, Beautiful Fighting Girl (Minneapolis: University of Wisconsin Press, (2011), 24-25

57 Mason, Mark. "Historiospectrography? Sande Cohen on Derrida's Specters of Marx. Rethinking History," 12, 4, (2008); 484-485

58 Paphitis, Tina. "Haunted Landscapes: Place, Past and Present," Time and Mind, 13:4 (2020); 341-344.

59 Murakami, Takahashi (ed.). Little Boy: The Arts of Japan's Exploding Subculture, (London: Japan Society, 2005), 168 
${ }^{60}$ In Bakemonogatari, the Hitagi Crab arc reveals that the character Senjougahara weighs a fraction of what she should as she is possessed by a crab deity. As this deity only affixes itself to those that wish to forget, it is revealed that Senjougahara has asked the deity to carry the trauma of her mother allowing a fellow cult member to sexually assault her as a child. As Senjougahara defended herself and injured the culprit, her mother was penalized by other cult members and her father divorced her. Senjougahara is thereby only exorcised when she confronts the trauma, accepts her emotional response, and asks the crab to return said response to her. Like Hachikuji, the crab deity simply grants a respite to those in need.

${ }^{61}$ Gowan, Todd. The End of Dissatisfaction: Jacques Lacan and the Emerging Society of Enjoyment, (Albany: State University of New York Press, 2003), 66-67; Zizek, Slavoj. Enjoy Your Symptom! Jacques Lacan in Hollywood and out, (New York: Taylor \& Francis, 2001), 10-12.

62 Takolander, Maria and Jo Langdon. "Shifting the "Vantage Point" to Women: Reconceptualizing Magical Realism and Trauma," Critique: Studies in Contemporary Fiction, 58, 1, (2017);46-47

63 Ibid, 41-44.

${ }^{64}$ Baudrillard, Jean. The Consumer Society and Structures, (London: Sage, 1998);

70-76.

65 Ibid, 87-92.

66 Ibid, 84-85.

${ }^{67}$ Girard, Rene. Things Hidden Since the Foundation of the World, (London: Bloomsbury); 312-313.

68 Derrida, Jacques. Specters of Marx, (New York: Routledge, 2012); 130-135.

69 Ibid, 10-11.

70 Hack, Brett. "Subculture as Social knowledge: A Hopeful Reading of Otaku Culture," Contemporary Japan, 28, 1 (2016); 34-35.

71 Baudrillard, Jean. The Consumer Society and Structures, (London: Sage, 1998); 38-41

72 Galbraith, Patrick W. "Moe: Exploring Virtual Potential in Post-Millennial Japan," electronic journal of contemporary japanese studies, (2009); 6.

${ }^{73}$ A tsundere is a subtype of moe-kyara. It is defined as a character being initially cold or aggressive, yet possessing a warm-hearted personality within.

74 Fisken, Tim. "The Spectral Proletariat: The Politics of Hauntology in The Communist Manifesto," Global Discourse, 2, 2 (2011); 27.

75 Baudrillard, Jean. The Consumer Society and Structures, (London: Sage, 1998); 86-90.

76 Ibid; 100-101

77 Ibid; 78-81.

78 Girard, Rene. Things Hidden Since the Foundation of the World, (London: Bloomsbury, 1987); 298-299.

79 Ibid, 276.

80 Ibid, 316.

${ }^{81}$ Baudrillard, Jean. The Consumer Society and Structures, (London: Sage, 1998); 25-29.

82 Ibid; 59-60.

83 Ibid; 31-35.

${ }^{84}$ Lamarre, Thomas. "Platonic Sex: Perversion and Shojo Anime (Part Two)," Animation: an interdisciplinary journal, 2:1 (2007); 19-22.

85 Girard, Rene. Things Hidden Since the Foundation of the World, (London: Bloomsbury, 1987); 304-306.

${ }^{86}$ Manovich, Lev. The Language of New Media. (Cambridge: The MIT Press, 2001); 96-106.

87 Ibid, 146-150.

${ }^{88}$ Gowan, Todd. The End of Dissatisfaction: Jacques Lacan and the Emerging Society of Enjoyment, (Albany: State University of New York Press, 2003),46-50.

${ }^{89}$ Kosmina, Brydie. "Feminist Temporalities: Memory, Ghosts, and the Collapse of Time," Continuum, 34, 6, (2020); 902. 
${ }^{90}$ Ruddell, Caroline. "From the 'Cinematic' to the 'Anime-ic': Issues of Movement in Anime," Animation: an interdisciplinary journal, 3, 2, (2008); 117-199; Saito, Tamaki, Beautiful Fighting Girl (Minneapolis: University of Wisconsin Press, 2011), 136-137.

${ }^{91}$ Nakagawa, Miho. "Mamoru Oshii's Production of Multi-layered Space in 2D Anime," Animation: An Interdisciplinary Journal, 8, 1, (2013) 65-66.

92 Ibid, 67-68.

${ }^{93}$ Beynon, David. "Superflat Architecture: Culture and Dimensionality," Art + Architectural Exchanges from East to West (2012); 1-4.

94 Jameson, Fredric. Postmodernism, or, The Cultural Logic of Late Capitalism, (Durham: Duke University Press, 2013), 25.

95 Ibid, 26.

${ }^{96}$ Ibid, 4.

${ }^{97}$ McCrea, Christian. "Explosive, Expulsive, Extraordinary: The Dimensional Excess of Animated Bodies," Animation: an interdisciplinary journal, 3, 1, (2008); 4.

${ }^{98}$ Ibid; $10-12$

${ }^{99}$ Ibid; 14-15.

${ }^{100}$ Ibid; 15-17.

${ }^{101}$ Hack, Brett. "Subculture as Social knowledge: A Hopeful Reading of Otaku Culture," Contemporary Japan, 28, 1 (2016); 41-42.

102 Galbraith, Patrick W. "Moe: Exploring Virtual Potential in Post-Millennial Japan,” electronic journal of contemporary japanese studies, (2009); 7.

103 Ibid, 4.

${ }^{104}$ Lamarre, Thomas. "Platonic Sex: Perversion and Shojo Anime (Part Two)," Animation: an interdisciplinary journal, 2:1 (2007); 10-12.

${ }^{105}$ Saito, Tamaki, Beautiful Fighting Girl (Minneapolis: University of Wisconsin Press, (2011); 27-29; Lamarre, Thomas. "Platonic Sex: Perversion and Shojo Anime (Part One)," Animation: an interdisciplinary journal, 1, 1, (2006); 57-58.

${ }^{106}$ Galbraith, Patrick W. "Moe: Exploring Virtual Potential in Post-Millennial Japan,” electronic journal of contemporary japanese studies, (2009); 2.

107 Ibid, 7.

${ }^{108}$ Fisken, Tim. "The Spectral Proletariat: The Politics of Hauntology in The Communist Manifesto," Global Discourse, 2, 2 (2011); 17-20.

${ }^{109}$ Derrida, Jacques. Specters of Marx, (New York: Routledge, 2012), 125-126.

110 Ibid, 147.

${ }^{111}$ Fisken, Tim. "The Spectral Proletariat: The Politics of Hauntology in The Communist Manifesto," Global Discourse, 2, 2 (2011); 17-20.

112 Kosmina, Brydie. "Feminist Temporalities: Memory, Ghosts, and the Collapse of Time," Continuum, 34, 6, (2020); 904-907.

${ }^{113}$ Lamarre, Thomas. "Platonic Sex: Perversion and Shojo Anime (Part One)," Animation: an interdisciplinary journal, 1, 1, (2006); 45-46; Akgun, Buket, "Mythology Moe-fied: Classical Witches, Warriors, and Monsters in Japanese Manga," Journal of Graphic Novels and Comics (2019):; 2-3.

${ }^{114}$ Derrida, Jacques. Specters of Marx, (New York: Routledge, 2012),155-162.

115 Baudrillard, Jean. Simulacra and Simulation, (Ann Arbor: University of Michigan Press, 1994), 96-98.

116 Ibid, 100-102.

${ }^{117}$ Ibid, 105

118 Ibid, 95 .

${ }^{119}$ Mason, Mark. "Historiospectrography? Sande Cohen on Derrida's Specters of Marx," Rethinking History, 12, 4, (2008); 493-495. 
${ }^{120}$ Glazier, Jacob. W. "Derrida and Messianic Subjectivity: A Hauntology of Revealability. Journal for Cultural Research, 21, 3, (2017); 242-244.

${ }^{121}$ Kosmina, Brydie. "Feminist Temporalities: Memory, Ghosts, and the Collapse of Time," Continuum, 34, 6, (2020); 908-910.

122 Gowan, Todd. The End of Dissatisfaction: Jacques Lacan and the Emerging Society of Enjoyment, (Albany: State University of New York Press, 2003), 53-56.

${ }^{123}$ Girard, Rene. Violence and the Sacred, (London: Bloomsbury, 2013), 25.

${ }^{124}$ Ibid, 26-27.

125 Ibid, 12-13.

${ }^{126}$ Greene, Barbara, "Reconstructing the Grand Narrative- The Pure Land of Madoka Magica," The Japanese Journal of Religious Studies, TBA (2021).

${ }^{127}$ Girard, Rene. Violence and the Sacred, (London: Bloomsbury, 2013), 48-54. 


\section{Bibliography}

Akgun, Buket. "Mythology Moe-fied: Classical Witches, Warriors, and Monsters in Japanese Manga." Journal of Graphic Novels and Comics (2019).

Azuma, Hiroki. Otaku: Japan's Database Animals. Jonathan E. Abel and Shion Kono (trans.). Minneapolis: University of Minnesota Press.2009.

Baudrillard, Jean. Simulacra and Simulation. Sheila Faria Glaser (trans.). Ann Arbor: University of Michigan Press, 1994.

Baudrillard, Jean. The Consumer Society and Structures. London: Sage, 1998.

Beynon, David. "Superflat Architecture: Culture and Dimensionality." Art + Architectural Exchanges from East to West 2012), 1-9.

Bolton, Christopher. Interpreting Anime. Minneapolis: University of Minnesota Press, 2018

Darling, Michael. "Plumbing the Depths of Superflatness." Art Journal, 60:3 (2001), pp. 76-89.

Deleuze, Gilles and Felix Gauttari. Anti-Oedipus: Capitalism and Schizophrenia. London: Penguin Books, 1977.

Derrida, Jacques. Specters of Marx. New York: Routledge, 2012.

Fisken, Tim. "The Spectral Proletariat: The Politics of Hauntology in The Communist Manifesto." Global Discourse, 2:2, (2011), 17-31.

Galbraith, Patrick W. "Moe: Exploring Virtual Potential in Post-Millennial Japan." electronic journal of contemporary japanese studies (2009).

Galbraith, Patrick W. Otaku and the Struggle for Imagination in Japan. Durham: Duke University Press, 2019.

Girard, Rene. Things Hidden Since the Foundation of the World. Stephen Bann and Michael Metteer (trans.). London: Bloomsbury, 1987.

Girard, Rene. Violence and the Sacred. Patrick Gregory (trans.). London: Bloomsbury, 2013. 
Glazier, Jacob. W. "Derrida and Messianic Subjectivity: A Hauntology of Revealability." Journal for Cultural Research, 21:3 (2017), 241-256.

Greene, Barbara. "Reconstructing the Grand Narrative- The Pure Land of Madoka Magica.” The Japanese Journal of Religious Studies, TBA, (2022)

Hack, Brett. "Subculture as Social knowledge: A Hopeful Reading of Otaku Culture." Contemporary Japan, 28:1 (2016), 33-57.

Horkheimer, Max and Theodor W. Adorno. Dialectic of Enlightenment: Philosophical Fragments. Edmund Jephcott (trans.). Stanford: Stanford University Press, 2002

Jameson, Fredric. Postmodernism, or, The Cultural Logic of Late Capitalism. Durham: Duke University Press, 2013

Kosmina, Brydie. "Feminist Temporalities: Memory, Ghosts, and the Collapse of Time." Continuum, 34:6 (2020), 901-913.

Lamarre, Thomas. "Platonic Sex: Perversion and Shojo Anime (Part One)". Animation: an interdisciplinary journal, 1:1 (2006), 45-59.

Lamarre, Thomas. "Platonic Sex: Perversion and Shojo Anime (Part Two).” Animation: an interdisciplinary journal, 2:1 (2007), 9-25.

Lyotard, Jean-Francois. The Postmodern Condition: A Report on Knowledge. Geoff Bennington and Brian Massumi (trans.). Manchester: Manchester University Press, 1984.

Manovich, Lev. The Language of New Media. Cambridge: The MIT Press, 2001.

Mason, Mark. "Historiospectrography? Sande Cohen on Derrida's Specters of Marx." Rethinking History, 12:4 (2008), 483-514.

McCrea, Christian. "Explosive, Expulsive, Extraordinary: The Dimensional Excess of Animated Bodies." Animation: an interdisciplinary journal, 3:1 (2008), 9-24.

McGowan, Todd. The End of Dissatisfaction: Jacques Lacan and the Emerging Society of Enjoyment. Albany: State University of New York Press, 2004.

"Monogatari Series Timeline and Watch Guide." Bakemonogatari Wiki, bakemonogatari.fandom.com/wiki/Monogatari_Series_Timeline_and_Watch_Gu ide\#Anime_Release_.2F_SHAFT_Order. 
Murai, Fumika 村井史香, Okamoto, Yuko 岡本祐子, Ota, Masayoshi 太田正義, and Kato Hiromichi 加藤弘通. “Relationship between Friendship with Self-Acknowledged Kyara and Self-Monitoring in Junior High School and University Students 中学生 • 大学生の“ 自認するキャラ”を介した友人関係とセルフ・モニタリングとの関連.” The Clinical Study of Childhood Development 子ども発達臨床研究. 15 (2021), 31-39.

Murakami, Takahashi (ed.). Little Boy: The Arts of Japan's Exploding Subculture. London: Japan Society, 2005.

Nakagawa, Miho. "Mamoru Oshii's Production of Multi-layered Space in 2D Anime." Animation: An Interdisciplinary Journal, 8:1 (2013), 65-83.

Oishi, Tatsuya (dir.). Bakemonogatari. Funimation, Aniplex, >https://www.funimation.com/shows/bakemonogatari<

Oyama, Makiko大山摩希子. “The Role of Character in Interpersonal Relationships in Modern Youth - Consideration from Relationships in Family, Close Friends, Friends, and Involvement with Club Activities 現代青年の対人関係におけるキャラの役割一家族 親友, 友人，部活における関わりからの考察一.” The Journal of Kansai University of Social Welfare 関西福祉大学研究紀要, 24 (2021), 41-50.

Paphitis, Tina. "Haunted Landscapes: Place, Past and Present." Time and Mind, 13:4 (2020), 341-349.

Ruddell, Caroline. "From the 'Cinematic' to the 'Anime-ic': Issues of Movement in Anime." Animation: an interdisciplinary journal, 3:2 (2008), 113-128.

Takolander, Maria and Jo Langdon. "Shifting the "Vantage Point" to Women: Reconceptualizing Magical Realism and Trauma." Critique: Studies in Contemporary Fiction, 58:1 (2017), 41-52.

Saito, Tamaki. Beautiful Fighting Girl. J. Keith Vincent and Dawn Lawson (trans). Minneapolis: University of Wisconsin Press, 2011.

Steinberg, Marc. "Otaku Consumption, Superflat Art and the Return to Edo." Japan Forum, 16:3 (2004), pp. 449-471.

Yamada, Marc. “The Database Imagination of Japanese Postmodern Culture.” Japanese Studies, 33:1 (2013), 19-37. 
Zizek, Slavoj. Enjoy Your Symptom! Jacques Lacan in Hollywood and out. New York: Taylor \& Francis, 2001. 